\title{
Single-Grain Si TFTs Fabricated by Liquid-Si and Long-Pulse Excimer-Laser
}

\author{
Ryoichi Ishihara ${ }^{\mathrm{a}}$, Jin Zhang ${ }^{\mathrm{a}}$, Miki Trifunovic ${ }^{\mathrm{a}}$, Michiel van der Zwan ${ }^{\mathrm{a}}$, \\ Hideyuki Takagishi $^{\mathrm{b}}$, Ryo Kawajiri ${ }^{\mathrm{b}}$, Tatsuya Shimoda ${ }^{\mathrm{b}, \mathrm{c}}$ and C.I.M. Beenakker ${ }^{\mathrm{a}}$ \\ ${ }^{a}$ Delft University of Technology, 2628 CT Delft, the Netherlands \\ b Japan Science and Technology Agency, ERATO, SHIMODA Nano-Liquid Process \\ Project, Ishikawa, 923-1211 Japan \\ ${ }^{c}$ School of Materials Science, Japan Advanced Institute of Science and Technology
}

(JAIST), Ishikawa, 923-1292 Japan

Solution process of silicon using liquid-Si is attractive for fabrication of high-speed flexible electronics. We have fabricated single-grain Si TFTs on location-controlled Si grains with longpulse excimer laser crystallization of spin-coated liquid Si film. The maximum grain diameter is $3.5 \mu \mathrm{m}$, and the mobilities for electrons and holes are $423 \mathrm{~cm}^{2} / \mathrm{Vs}$ and $118 \mathrm{~cm}^{2} / \mathrm{Vs}$, respectively.

\section{Introduction}

Printed flexible electronics will open novel applications with a lower cost compared with the vacuum- and photolithography-based process. While printed organic TFTs have been improving their performance in the last decade [1,2], the carrier mobility and reliability are much inferior in comparison with silicon devices. Liquid silicon [3] is a solution of hydrogenated polysilane, which realizes printing process of Si devices. This would lead to novel application of printed high-speed flexible electronics, for example, a super e-paper [4], and may influence the VLSI industry as well.

In 2006, Shimoda, et al., have reported that using liquid silicon amorphous Si can be printed and poly-Si TFTs have been fabricated with pulsed laser crystallization of the layer [3]. However the performance is limited by the grain boundaries in the channel because of the randomly positioned poly-Si grains. We have fabricated single-grain (SG) $\mathrm{Si}$ TFTs in location-controlled Si grains, which are formed with the $\mu$-Czochralski process [5] with the spin-coated liquid-Si. Si grains with a diameter of $1.6 \mu \mathrm{m}$ at predetermined positions, and TFTs with the mobilities of $391 \mathrm{~cm}^{2} / \mathrm{Vs}$ and $111 \mathrm{~cm}^{2} / \mathrm{Vs}$ for the electrons and holes, respectively, have been achieved [6].

In this study, we have used a long-pulse excimer-laser for crystallization of the a-Si printed using the liquid-Si for further improvements in the grain size and field-effect mobilities.

\section{Solution process of silicon}

First we review solution process of silicon with two approaches. One is an approach using silicon nano-particle and the other is using the liquid-Si.

\section{$\underline{\text { Nano-particle }}$}

For solution process of silicon, silicon nano-particle dispersed solutions with an organic solvent have been commonly used [7]. After coating the solution on a substrate and drying the solvent, silicon layer can be formed. However, because of the large surface 
area of the nano-particle, relatively thick native oxide has formed on the surface. There are also many voids formed between the particles. The native oxide and voids impede carrier motion in the layer and the conductivity becomes significantly lowered [8].

\section{$\underline{\text { Liquid-Si }}$}

Shimoda et al., proposed solution process of $\mathrm{Si}$ based on cyclopentasilane (CPS) solution [3]. The CPS is a cyclic-compound having only $\mathrm{Si}$ and $\mathrm{H}$ atoms $\left(\mathrm{Si}_{5} \mathrm{H}_{10}\right)$ as shown in the chemical structure of Fig 1. It is transparent liquid at room temperature and decomposes to form a-Si when heated to $300^{\circ} \mathrm{C}$ or higher. However, the boiling point $\left(194^{\circ} \mathrm{C}\right)$ of $\mathrm{CPS}$ is less than $300^{\circ} \mathrm{C}$ and therefore it evaporates before the thermal decomposition occurs, which makes the solution processing difficult. The boiling point can be increased by introducing polymeric hydrogenated polysilanes, $-\left(\mathrm{SiH}_{2}\right)_{\mathrm{n}}-$, which increases the molecular weight. They have applied photo-induced ring-opening polymerization to obtain pure hydrogenated polysilanes from the CPS. By diluting the solution with an organic solvent, such as toluene, they obtained the solution, which is referred to as liquid silicon. When the spin-coated liquid-Si layer is heated, organic solvent and CPS evaporate first and then the $\mathrm{Si}-\mathrm{Si}$ bonds in the polysilane begin to break. After that, at around $300^{\circ} \mathrm{C}$, the $\mathrm{Si}-\mathrm{H}$ bonds break, resulting in a three-dimensional a- $\mathrm{Si}$ network. When the a-Si film is further baked at $540^{\circ} \mathrm{C}$ for $2 \mathrm{~h}$, it contains only 0.3 at $\%$ hydrogen, which is ideal precursor a-Si for the laser crystallization.

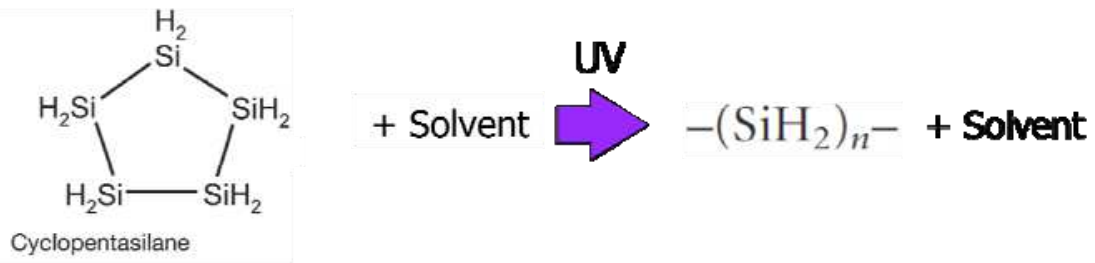

Figure 1. Chemical equation for preparation of liquid-Si from cyclopentasilane

\section{Experimental}

We used the $\mu$-Czochralski process [3] to control the position of Si grains. Fig. 2 shows a schematic view illustrating the fabrication process. First, a grid of $100 \mathrm{~nm}$ wide and $700 \mathrm{~nm}$ deep holes (grain-filter) have been formed in $1.6 \mu \mathrm{m}$ thick $\mathrm{SiO}_{2}$ on a crystalline Si substrate. 21-wt\% solution of UV irradiated CPS (liquid Si) was then spincoated on the structure at a rotation speed of $2000 \mathrm{rpm}$ (Fig. 2(a)) and baked at $430^{\circ} \mathrm{C}$ for $60 \mathrm{~min}$ to remove the solvent and to form a-Si. (Fig. 2(b)) Raman spectroscopy showing a peak at $480 \mathrm{~cm}^{-1}$ proves that it is an a-Si film. The film thickness was $112 \mathrm{~nm}$. It was found that the grain-filters are filled by the liquid silicon completely. Next the film was pre-annealed in a furnace at $650^{\circ} \mathrm{C}$ for 2 hours to dehydrogenate the a-Si film. After the annealing, hydrogen concentration of a-Si film measured with TOF-SIMS (Time-ofFlight Secondary Ion Mass Spectrometry) was decreased from $6.7 \times 10^{21} \mathrm{~cm}^{-3}$ to $2-5 \times 10^{19}$ $\mathrm{cm}^{-3}$. The thickness of the film decreased to $88 \mathrm{~nm}$. 


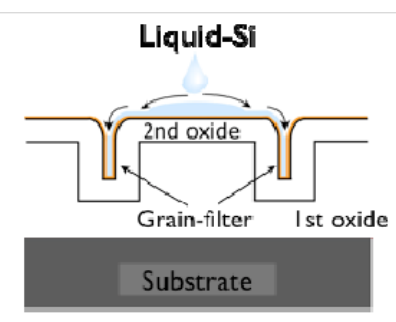

(a)

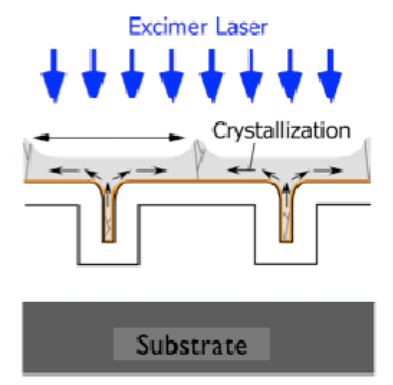

(c)

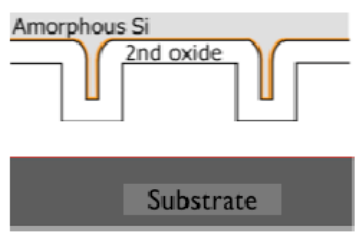

(b)

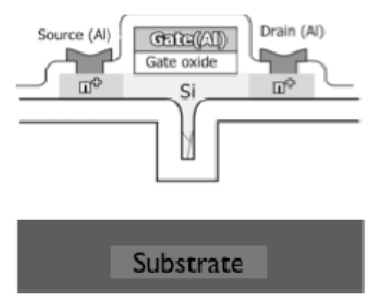

(d)

Figure 2. Schematic drawings of the combined liquid-Si and $\mu$-Czochralski process

Then the film was crystallized with $\mathrm{XeCl}$ excimer with a pulse-duration of $250 \mathrm{~ns}$ at a substrate temperature of $450^{\circ} \mathrm{C}$. As shown in Fig. 3, Si grains were obtained on the predetermined position of the grain filters with the maximum grain size of $3.5 \mu \mathrm{m}$. Compared with the short-pulse (25ns) excimer-laser case [6], the grain-size was increased. This is because nucleation outside of the grain, which limits the grain size, is delayed due to increase in the amount of heat accumulated near the surface and hence slow cooling rate of the molten-Si.

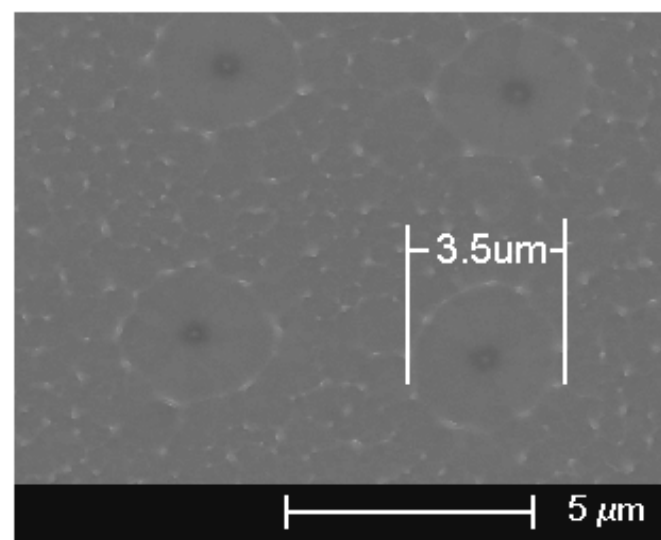

Figure 3. SEM image of location-controlled Si grains

Then TFTs are fabricated inside the single-grain with the same process described in [6]. $41 \mathrm{~nm}$ thick gate $\mathrm{SiO}_{2}$ is formed by ICP oxidation at $250^{\circ} \mathrm{C}$ and successive PECVD using TEOS at $350^{\circ} \mathrm{C}$. After aluminum gate formation, source and drain region were doped with $1 \times 10^{16}$ ions $/ \mathrm{cm}^{2}$ boron at $20 \mathrm{keV}$ for PMOS and $1 \times 10^{16}$ ions $/ \mathrm{cm}^{2}$ phosphorus implantation at $70 \mathrm{keV}$ for NMOS transistors. The dopants are activated using the $\mathrm{XeCl}$ excimer laser at a fluence of $300 \mathrm{~mJ} / \mathrm{cm}^{2}$. Aluminum pads formation completed the process. The width and the length of the TFTs are both $1 \mu \mathrm{m}$. 


\section{Results and Discussions}

Electrical characteristics of the SG Si TFTs were measured. Figure 4 shows the transfer characteristics of NMOS and PMOS SG-TFTs. The carrier mobilities, which were estimated in the linear region at a low drain voltage, are $423 \mathrm{~cm}^{2} / \mathrm{Vs}$ for the electrons and $118 \mathrm{~cm}^{2} / \mathrm{Vs}$ for the holes. The carrier mobilities increased profoundly compared to those of the poly-Si TFTs [3] because the location-controlled silicon grain realized the channel region inside one single grain. The mobilities are slightly increased from our previous publication [6] as a result of the longer pulse duration of excimer-laser.

Figure 5 shows the output characteristics of both types of TFTs. While PMOS shows a readily increase in the drain current (Fig.5(b)), NMOS shows slight current-crowding indicating parasitic resistance (Fig.5(a)). This is caused by the relatively thinner Si film thickness than our previous study [9].

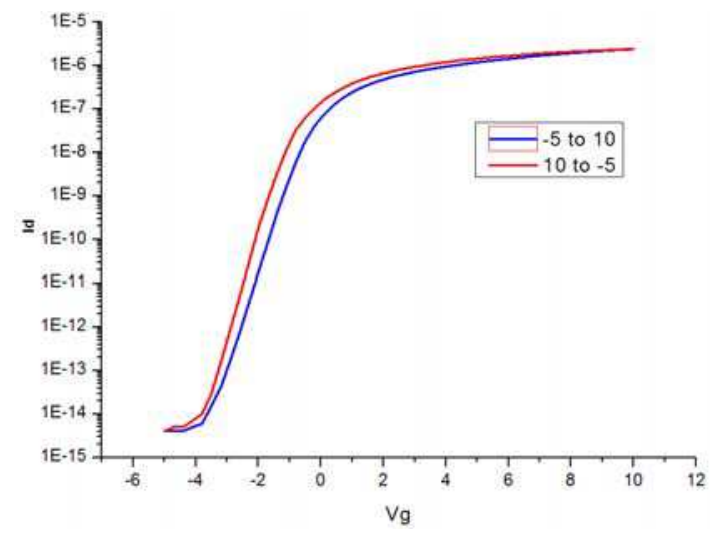

(a)

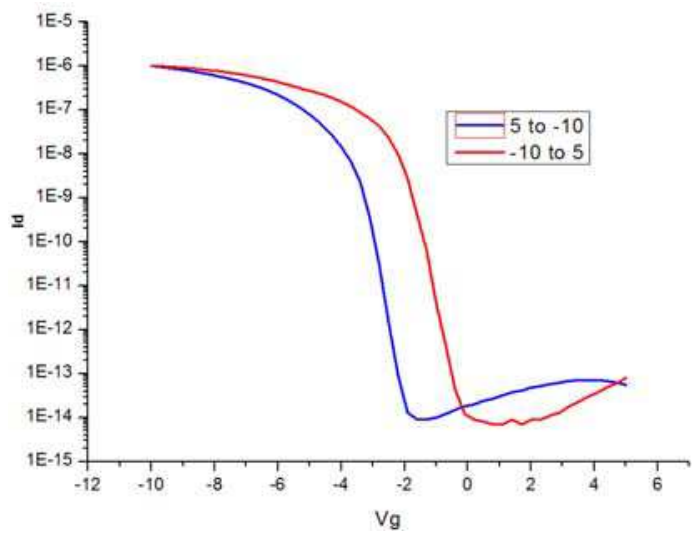

(b)

Figure 4. Transfer characteristics of $\mathrm{N}$ (a) and P (b) MOS SG TFTs (Vds=0.02Vfor NMOS and Vds=-0.02V for PMOS)

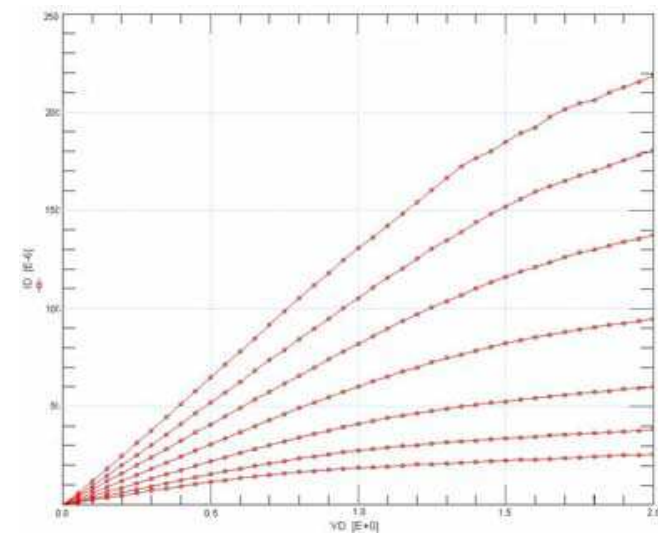

(a)

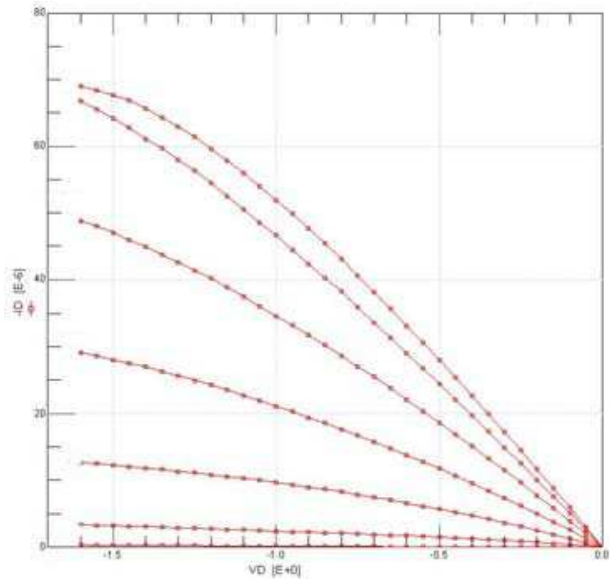

(b)

Figure 5. Output characteristics of N (a) and P (b) MOS SG TFTs 
Figure 6 shows the mobilities of the holes and electrons as a function of the laser fluences. Optimum mobilities for electron and hole were obtained at $1000 \mathrm{~mJ} / \mathrm{cm}^{2}$ and $1050 \mathrm{~mJ} / \mathrm{cm}^{2}$, respectively. Mobility decreases in higher energy densities are presumably caused by surface roughness.

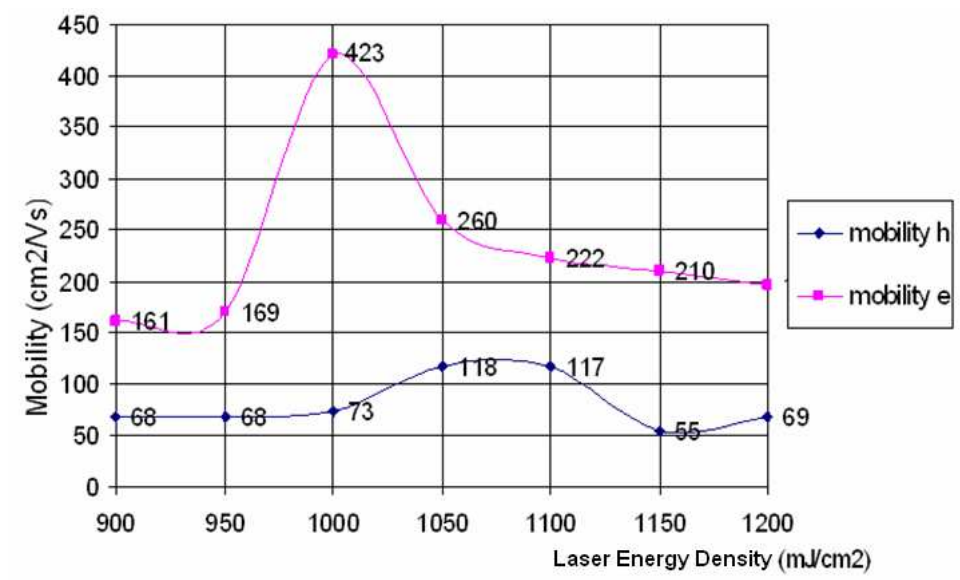

Figure 6. Carrier mobilities vs. laser crystallization energy density

\section{Conclusions}

We have fabricated single-grain Si TFTs on location-controlled Si grains with long-pulse excimer laser crystallization of spin-coated liquid $\mathrm{Si}$ film. The maximum grain diameter is $3.5 \mu \mathrm{m}$, and the mobilities for electrons and holes are $423 \mathrm{~cm}^{2} / \mathrm{Vs}$ and $118 \mathrm{~cm}^{2} / \mathrm{Vs}$, respectively.

\section{Acknowledgments}

The authors acknowledge STW (The Dutch Technology Foundation) for their financial support for this study.

\section{References}

1. G. Gelink, et al., Nature Mater., 3 (2004) 106

2. J. Soeda, et al., Adv. Mater. 23, 3681-3685 (2011)

3. T. Shimoda, et al., Nature, 440 (2006) 783

4. R. Ishihara, et al., Proceedings of SPIE, 7956, (2011)

5. R. Ishihara, et al., Thin Solid Film, 427 (1-2), 77 (2003)

6. J. Zhang, et al., Tech. Dig. IEDM, 14.5.1 - 4 (2011)

7. L. Mangolini, et al., Adv. Mater. 19, 2513 (2007)

8. Y. Nakamine, et al., IEEE Silicon Nanoelectronics Workshop (2011)

9. V. Rana, et al., IEEE Trans. Electron. Devices, 52 (12), 2622 (2004) 